
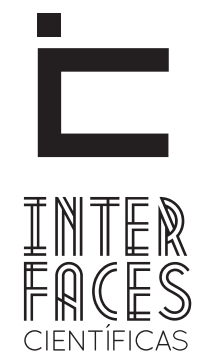

EDUCAÇÃO

ISSN IMPRESSO 2316-333X

ISSN ELETRÔNICO 2316-3828

PARTE 2 - FORMAÇÃO E ATUAÇÃO PROFISSIONAL DA EDUCAÇÃO SOCIAL

\title{
A EDUCAÇÃO SOCIAL EM PORTUGAL: NOVOS DESAFIOS PARA A IDENTIDADE PROFISSIONAL
}

Fátima Correia ${ }^{1}$

Teresa Martins ${ }^{2}$
Sílvia Azevedo ${ }^{3}$

Paulo Delgado ${ }^{4}$

\section{RESUMO}

A Educação Social surge, em Portugal, devido sobretudo à exigência dos sistemas de proteção social. Enquanto profissão, a Educação Social realiza-se no âmbito das ciências da educação, enquadrada pela Pedagogia Social. A Educação Social desenvolve-se pela diversidade de categorias profissionais e de perfis de competências e áreas disciplinares. 0 reconhecimento da identidade profissional dos educadores sociais portugueses depende, ainda, da polivalência dos contextos de trabalho e populações com os quais interage. A sua identidade profissional deve evidenciar o compromisso educativo do seu trabalho social, que supera lógicas de ação assistencialistas e se centra em lógicas de desenvolvimento e capacitação dos sujeitos. Neste artigo, é dado destaque à Pedagogia Social, enquanto saber matricial de referência dos educadores sociais. A Pedagogia Social constitui-se como a ciência da Educação Social, conferindo-lhe a própria especificidade da profissão. Por outro lado, o exercício profissional da Educação Social requer dos seus profissionais uma formação rigorosa, inicial e contínua, de forma a incorporar novos saberes e posturas para se adaptar a novos desafios e realidades. A educação social deve ser capaz de acompanhar as políticas sociais, participando permanentemente na negociação do contrato social. Partindo destes pressupostos, é dado a conhecer alguns desafios que se colocam à Educação Social em Portugal.

\section{PALAVRAS-CHAVE}

Educação Social. Pedagogia Social. Identidade Profissional. Portugal. Desafios Profissionais 


\section{RESUMEN}

La Educación Social emerge en Portugal, debido sobre todo a la exigencia de los sistemas de protección social. Como profesión, la Educación Social se realiza en el ámbito de las ciencias de la educación, encuadrada por la Pedagogía Social. La Pedagogía Social se desarrolla por la diversidad de categorías profesionales y de los perfiles de las competencias y áreas disciplinarias. El reconocimiento de la identidad profesional de los educadores sociales portugueses depende, aun, de la polivalencia de los contextos del trabajo y poblaciones con los cuales interactúan. Su identidad profesional de poner en evidencia el compromiso educativo de su trabajo social, que supera la lógica de la acción asistencialista y se centra en la lógica del desarrollo y capacitación de los sujetos. En este artículo es destacada la Pedagogía Social, como un saber que es referencia para los educadores sociales.
La Pedagogía Social se constituye como la ciencia de la Educación Social dotándolo la propia especificidad de la profesión. Además, el ejercicio profesional de la Educación Social requiere de sus profesionales una formación precisa, inicial y continua, para incorporar nuevos saberes y posturas para que se adecuen a los nuevos retos de la contemporaneidad. La educación social tiene que ser capaz de seguir las políticas sociales, participando permanentemente en la negociación del contrato social. A partir de estos presupuestos, se puede conocer algunos retos que se pongan a la Educación Social en Portugal.

\section{PALABRAS-CLAVE:}

Educación Social. Pedagogía Social. La identidad Profesional. Portugal. Retos Profesionales.

\section{ABSTRACT}

The Social Education comes in Portugal, mainly due to the requirement of social protection systems. As a profession, the Social Education takes place in the context of science education, framed by the Social Pedagogy. The Social Education develops the diversity of professional categories and skills and disciplines profiles. The recognition of professional identity of the Portuguese social workers also depends on the versatility of work contexts and populations with which it interacts. Their professional identity should highlight the educational commitment of its social work, which surpasses logic welfare action and focuses on logical development and training subjects. In this article, emphasis is given to the Social Pedagogy, while knowing reference matrix of social educators. The Social Pedagogy was established as the science of Social Education, giving it the very specificity of the profession. On the other hand, the professional practice of Social Education requires its professionals a rigorous initial and ongoing training in order to incorporate new knowledge and attitudes to adapt to new challenges and realities. The social education should be able to monitor social policies, constantly participating in the negotiation of the social contract. Under these assumptions, is made known some challenges facing the Social Education in Portugal.

\section{KEYWORDS}

Social Education. Social Pedagogy. Professional Identity. Portugal. Professional Challenges. 


\section{ECLOSÃO E EXPANSÃO DA EDUCAÇÃO SOCIAL EM PORTUGAL}

A Educação Social, como a concebemos atualmente, é uma profissão relativamente recente em Portugal. Contudo, a sua origem está associada à industrialização e aos problemas que dela decorreram, nomeadamente os problemas de desigualdade social, que exigiram a necessidade de dar respostas inovadoras aos problemas sociais que iam surgindo numa sociedade cada vez mais complexa. A industrialização despoletou um conjunto de mudanças sociais, dando uma nova dimensão ao trabalho: o trabalho "estável" passa a ser associado a uma inserção "sólida" na sociedade, ao passo que a precaridade laboral, que se associa à vulnerabilidade social, é potencialmente produtora de exclusão social (AZEVEDO e CORREIA, 2013).

A crescente complexidade da sociedade e o aumento das bolsas de pobreza nos grandes centros urbanos culmina com uma agudização dos fenómenos de marginalização e exclusão social (RAMOS, 2006). Contudo, embora estes sejam fatores da eclosão da Educação Social, a sua expansão resultou de outros fatores, nomeadamente os novos movimentos sociais e a reconfiguração do Estado, mais consciente da sua responsabilidade face aos problemas sociais e com novas políticas sociais que se afastam de intervenções mais tradicionais e assistencialistas. 0 trabalho social passa a ser mais do que apoiar os cidadãos com recursos materiais para passar a promover a autonomia, o empowerment e a emancipação do sujeito, rompendo com o assistencialismo, o emergencialismo e a caridade (AZEVEDO e CORREIA, 2013). A exigência dos sistemas de proteção social é, na verdade, o principal impulsionador da Educação Social enquanto ação psicossocial e educativa.

Foi no final da Segunda Guerra Mundial que surgiu o ideal de vida em sociedade, mediante a definição de regras de convivência reguladas por um Estado protetor que assegurasse a ordem pública e estivesse ao serviço de todos os cidadãos, garantindo o acesso a um número mínimo de serviços. Surge, assim, o Estado-Providência, associado à democracia e uma maior consciencialização e responsabilidade dos poderes políticos em relação aos problemas e direitos sociais das populações (DÍAZ, 2006). A expansão do Estado-Providência decorre num cenário de progressiva valorização dos Direitos Humanos, de implantação de medidas de política social que atendem, progressivamente, aos ideais humanitários de igualdade de oportunidades e justiça social (TIMÓTEO, 2013). Com efeito, a universalidade dos Direitos Humanos assenta na liberdade e na dignidade da pessoa humana. Neste prisma, toda a pessoa é sujeito de direitos, assim como dos deveres que aqueles comportam (PÉREZ SERRANO, 2005).

Em termos jurídicos, a Educação Social foi impulsionada por três grandes marcos: a Declaração Universal dos Direitos do Homem, aprovada em 1948, que proclama a igualdade de todos os cidadãos; a Declaração dos Direitos da Criança, que consagra a responsabilidade dos Estados e da sociedade no futuro das crianças e jovens, assegurando nomeadamente o direito da igualdade, à educação e a crescer num ambiente de afeto e segurança; e a Convenção dos Direitos da Criança, que completa a Declaração dos Direitos da Criança, reforçando a responsabilidade do Estado na proteção de crianças privadas de um adequado ambiente familiar (DÍAZ, 2006).

Destacamos, ainda, nos fatores que justificam a expansão da Educação Social, a mudança do conceito de educação. Com efeito, a educação deixa de ser encarada como património exclusivo da escola e passa a ser entendida como um processo contínuo, de aprendizagem ao longo da vida, aproximando-se da dimensão social e assumindo novas funções. Paralelamente aos sistemas formais de ensino-aprendizagem, são 
reconhecidos e definidos os contextos de educação não-formal e informal, enquanto âmbitos essenciais do desenvolvimento humano e da construção da cidadania. A educação e o desenvolvimento são processos que não se esgotam na formalidade da educação, passando-se a equacionar a diversidade dos contextos sociais e a forma como o indivíduo se relaciona com o meio que o rodeia (SERAPICOS, 2006).

Em Portugal, a investigação na área das ciências da educação desenvolve-se nas décadas de setenta e oitenta. No âmbito das ciências da educação, enquadrada pela pedagogia social, surge a Educação Social, nas escolas profissionais, enquanto formação técnico-profissional, com equivalência ao $12^{\circ}$ ano de escolaridade. Os educadores sociais eram entendidos como meros monitores que acompanhavam crianças e adolescentes, muitas vezes com incapacidades físicas, psíquicas e problemas de comportamento, dinamizando atividades lúdicas e não tendo qualquer tipo de formação para a decisão e acompanhamento de casos (AZEVEDO, 2011).

Nas décadas de 1980 e 1990, proliferam os primeiros cursos de nível superior em educação social, que atribuíam o título de bacharel, com a duração de três anos, iniciados pelas Escolas Superiores de Educação do Porto e de Santarém. A educação social, de nível técnico-profissional e bacharel, tinha como finalidade desenvolver atividades recreativas para diferentes tipos de população, utilizando uma metodologia centrada na animação social e cultural (AZEVEDO, 2011). A pertinência da Educação Social foi-se acentuando, cada vez mais, e, em 1996, foi homologada a primeira licenciatura em Educação Social, que perspetiva a atuação perante indivíduos, grupos e/ou comunidades, crianças, jovens, adultos e idosos numa perspetiva de prevenção e reabilitação dos problemas sociais. 0 educador social passa a realizar apoio educativo, pedagógico, social e formativo a estes públicos no sentido de desenvolver competências sociais (AZEVEDO, 2011). A partir daqui, são criadas as licenciaturas em Educação Social em várias instituições públicas e privadas de ensino superior. A formação superior permite uma preparação mais aprofundada e integrada dos futuros profissionais, mediante os estágios curriculares que possibilitaram a abertura de novos campos de atuação, a articulação entre teoria e prática e o desenvolvimento de projetos concebidos localmente (TIMÓTEO, 2013).

Em suma, num curto espaço de tempo, a educação social deixa de estar associada a uma perspetiva técnica e recreativa e passa a ser associada a uma perspetiva de intervenção social e pedagógica (TIMÓTEO, 2013). Este é um dos primeiros desafios dos educadores sociais portugueses: a confusão e confronto devido a diferentes categorias profissionais e académicas. Atualmente continuam a existir técnicos com formação profissional e bacharéis que labutam como educadores sociais distintos dos técnicos superiores de educação social com formação ao nível da licenciatura e, por isso, com um enquadramento profissional distinto.

Por outro lado, a esta diversidade de categorias profissionais, podemos acrescentar ainda a diversidade de perfis de competências e áreas disciplinares das licenciaturas em Educação Social e áreas afins. Embora com o Tratado de Bolonha tenha existido uma certa uniformização dos cursos, a verdade é que este processo não foi acompanhado de uma estratégia profissional. De acordo com Canastra (2011, p. 21), não existe um referente mínimo comum às diferentes formações, existindo diferenças “quer em termos de matriz disciplinar específica, quer no que toca ao perfil de saída”. Além disso, surgem outras licenciaturas com designações que remetem para a educação social, como é o caso da licenciatura em Educação Socioprofisisonal ou Educação Social Gerontológica (CANASTRA, 2011).

0 reconhecimento da identidade profissional dos educadores sociais portugueses, contudo, não depende só das dificuldades inerentes à forma como a profissão evoluiu academicamente, mas também devido 
à ampla diversidade de contextos e populações com os quais interage, pois dificulta a delimitação do seu campo de intervenção. Se na emergência da educação social, o educador social apenas lidava com um público muito específico, o seu domínio de intervenção é muito mais abrangente (CAPUL \& LEMAY, 2003), uma vez que intervém com populações de todas as faixas etárias, que vão desde a infância e juventude à adultez e velhice; intervém com pessoas e grupos com problemas específicos, como por exemplo toxicodependentes ou pessoas que se prostituem; intervém em meio aberto, como sucede na intervenção comunitária e com sem abrigo, em meio semi-aberto, como é o caso dos centros de dia, e meio fechado, como os estabelecimentos prisionais; intervém ao nível da prevenção primária, secundária e terciária e da inserção social, profissional, escolar, ao nível da saúde, da cultura, da educação e formação de adultos, da ocupação de tempos livres; intervém em contextos como a rua, a escola, a comunidade, a família e as instituições. Tudo isto faz com que o seu domínio de intervenção "não apresente limites bem definidos” (CAPUL \& LEMAY, 2003, p. 7).

Se por um lado, esta polivalência dos contextos de trabalho do educador social, a multiplicidade de papéis e pluralidade de competências que este pode assumir poderiam facilitar a empregabilidade, por outro lado, dificultam uma definição clara e criteriosa do seu campo de ação e funções, não facilitando o processo de construção e afirmação pública da identidade profissional enquanto técnico especializado e, consequentemente, gerando incertezas na contratação. Não obstante, a profissionalização dos educadores sociais faz-se ainda num movimento de aproximação e demarcação com outros profissionais (BAPTISTA, 2001).

Os educadores sociais encontram ainda grandes dificuldades de inserção laboral não pela falta de territórios de intervenção, mas pela confusão com outros profissionais, cuja profissão está mais consolidada e aceita no universo da ação social, como sucede com os assistentes sociais ou com os animadores socioculturais e outros de aparente semelhança de títulos.
Na verdade, os educadores sociais são trabalhadores sociais, na medida em que partilham o mesmo território de intervenção e os mesmos públicos com estes profissionais, mas o trabalho social desenvolvido pelos educadores sociais, embora desenvolvido em contextos sociais, é concebido a partir de uma perspetiva educativa e pedagógica, aproximando-se dos professores/educadores. Um dos desafios dos educadores sociais é, assim, o de definir uma identidade profissional que evidencie o compromisso educativo do seu trabalho social, que supera lógicas de ação assistencialistas e se centra em lógicas que perspetivem a capacitação dos sujeitos e o seu desenvolvimento.

O reconhecimento do estatuto profissional do educador social passará, inevitavelmente, pela definição clara de funções que este profissional desempenha, evitando a imprecisão e ambiguidade que carateriza a sua identidade profissional. Cabe-nos aqui destacar que o papel do educador social é fundamentalmente pedagógico, recorrendo à sua referência matricial de excelência: a Pedagogia Social, enquanto saber epistemologicamente indexado às ciências da educação (BAPTISTA, 2001). Este é, na verdade, um outro desafio dos educadores sociais portugueses: a clarificação do seu conhecimento epistemológico.

Os educadores sociais têm um saber próprio, pedagógico, técnico e humano, que urge implementar cada vez mais nas suas práticas profissionais. A Pedagogia Social é uma ciência de caráter teórico-prático que se refere à socialização do indivíduo (DÍAZ, 2006). Deve, por isso, ser encarada como uma disciplina científica, a "ciência da educação social”, dirigida a indivíduos e grupos, ao centrar-se nos problemas humano-sociais e a entendê-los como suscetíveis de serem tratados a partir de instâncias educativas, na implementação de projetos de intervenção socioeducativa assentes na investigação-ação (PÉREZ SERRANO, 2009). Contudo, embora a Pedagogia Social constitua um ponto fundamental do campo científico da educação social, esta disciplina nem sempre aparece formalmente contemplada nos planos de estudo dos cursos de formação inicial e contínua em educação social. 
A Pedagogia Social e a Educação Social estão ligadas num ponto onde confluem a teoria e a prática. Falar em Educação Social é falar de um conjunto de ações educativas, que incidem em situações concretas da realidade social, com a finalidade de alcançar ou atingir objetivos, previamente pensados, ao contrário da Pedagogia Social, que é uma fundamentação filosófica, ou seja, de teorização normativa.

A pedagogia social é, para os educadores sociais portugueses, mais do que uma simples estratégia de intervenção ou disciplina, pois é ela que assegura as bases de uma atuação pedagógica, dando-lhe modelos de conhecimento, metodologias e técnicas que permitem aos educadores sociais promoverem as condições de educabilidade de todas as pessoas, em particular das mais vulneráveis. Deste modo, a educação social está sustentada numa ciência que a conceptualiza, investiga e sistematiza os conhecimentos a ela associados (DÍAZ, 2006). As intervenções dos educadores sociais só serão eficientes se existirem teorias e modelos que sustentem a ação. A pedagogia social cumpre todos estes requisitos. Segundo Caride (2005), estamos face a uma ciência em (re)construção, atendendo às realidades socioculturais e econômicas em que inscreve as suas atuações, com um objeto, um método e fontes próprias, que intervém para transformar a realidade, promovendo políticas socioeducativas que têm nos direitos humanos um pilar orientador.

A identidade profissional dos educadores sociais portugueses depende, também, de uma definição clara do seu conceito, uma vez que não há uma forma unívoca de entender a educação social. A educação social está associada a um espaço e tempo concreto e ao contexto social e às políticas dominantes. Por este motivo, a educação social efetiva-se em todos os contextos nos quais se desenvolve a vida do sujeito. Na verdade, a própria educação e o desenvolvimento são processos que decorrem desde o nascimento até à morte.
A Educação Social tem raízes na antiguidade remota,

Coincidente com as primeiras preocupações dos seres humanos por formar-se como indivíduos que vivem num grupo e numa comunidade, para se desenvolverem como pessoas e participarem na vida comunitária de que formam parte, sem que se estabelecesse - de modo explícito - um tempo para a educação e outro tempo para a vida. (CARIDE, 2005, p. 117).

A Pedagogia Social, enquanto campo que estuda e enquadra a educação social, surge na Alemanha, em resultado da Revolução Industrial e da crise bélica que se viveu nos inícios do século XX. Estas motivaram problemas sociais como o desemprego, a proletarização ou os fluxos migratórios, que exigiram novas respostas educativas. A expressão Pedagogia Social foi utilizada pela primeira vez por Diesterweg, que também utilizou pela primeira vez o conceito de educação social, embora não a tenha voltado a utilizar e que, por isso, pode ter-se tratado de um uso casual.

No entanto, o autor mais importante desta primeira etapa da Pedagogia Social foi Natorp, que defendia a ideia de que o homem só existe na comunidade que o envolve, que, por sua vez, lhe permite o progresso. Natorp (2001, p. 34) coloca ênfase no ser humano enquanto ser social, uma vez que "o homem, no que respeita a tudo o que faz dele um homem, não se apresenta no início como indivíduo particular para entrar depois com outros numa comunidade, uma vez que, sem esta comunidade, não é de nenhum modo homem". Por este motivo, a pedagogia só fazia sentido se fosse social.

Com a Primeira Guerra Mundial, surgem problemas como o desemprego, delinquência, falta de proteção social, sobretudo da infância e juventude, que motivam o surgimento de uma pedagogia social relacionada com a política. Nohl concebe a pedagogia social a partir de uma perspetiva preventiva e de desenvolvimento das suas capacidades. A Pedagogia Social foi, ainda, utilizada como propaganda política, 
aquando o nacional-socialismo de Hitler. Por fim, surge a pedagogia social crítica que parte de uma situação concreta, analisando-a e refletindo sobre ela no sentido de a transformar. Esta perspetiva da Pedagogia Social entende-a como sendo relacional, unindo a teoria à prática, que se influenciam mutuamente ao ponto de se transformarem dialeticamente. A pedagogia social crítica pretende, deste modo, a emancipação humana (DÍAZ, 2006).

A dificuldade em definir o conceito de educação social é reforçada pela evolução da Pedagogia Social, que descrevemos de modo sintético, e que motiva o aparecimento de duas tradições históricas na Educação Social (CABANAS, 1998). De acordo com uma das perspetivas, a educação social é entendida como "formação para a socialização", na qual se pretende inseriro indivíduo na comunidade e ensinar-lhe as regras de convivência, educando-o como "naturalmente destinado a viver em sociedade" (AMADO, 1920 apud CABANAS, 1998, p. 74).

Nesse sentido, a educação social é um processo de transmissão de valores educativos, de normas e valores necessários para a ordem social (PETRUS, 1998). Esta perspetiva aproxima a educação social de uma didática do social, como uma ciência da intervenção face aos problemas sociais, de prevenção e controlo social face ao desvio social. Numa outra perspetiva, entende-se a Educação Social como um trabalho social e educativo, numa visão mais ampla quer de prevenção quer de ressocialização, tendo por base uma lógica interdisciplinar.

Assim, a educação social constitui-se como uma ação profissional qualificada, próxima da inadaptação social (PETRUS, 1998). Convém salientar, no entanto, que enquanto a primeira perspetiva da educação social, ao focar-se apenas nos resultados e na lógica de "tratamento" dos problemas sociais, ignora os processos, inibindo a reflexão e o questionamento (DÍAZ, 2006), a segunda visão estabelece uma aproximação excessiva entre educação social e intervenção junto de sujeitos que vivem "à margem" da sociedade, esquecendo outros campos na área da educação social, como a promoção da qualidade de vida e a adoção de estratégias de prevenção dos desequilíbrios sociais (DÍAZ, 2006).

Importa aqui reforçar que a Pedagogia Social permite aos educadores sociais encontrar novas respostas educativas perante os desafios que surgem na sociedade atual, uma vez que tem por objeto de estudo formal e abstrato a educação social dos indivíduos, que deve ajudar a formar e a integrar na sociedade (CARIDE \& TRILLO, 2010). É esta matriz de referência que especifica a Educação Social, conferindo-lhe uma relação de proximidade com os indivíduos que se reveste como mais do que um recurso técnico: é a própria especificidade da profissão.

Portanto, se os educadores sociais pretendem constituir uma identidade profissional distinta de outros profissionais deverão recorrer mais frequentemente às funções educativas da sua profissão. Com efeito, é o compromisso educativo da Educação Social que possibilita aos sujeitos serem protagonistas do seu próprio desenvolvimento, partindo dos seus saberes e de uma participação consciencializada. A participação é, talvez, o conceito mais importante do trabalho social e educativo deste profissional, pois é mediante esta que o sujeito se integra no seu meio social, com capacidade crítica para o melhorar e transformar (TIMÓTEO, 2013).

A educação social é entendida como uma progressiva e contínua configuração do indivíduo para alcançar o seu desenvolvimento e autonomia pessoal e conseguir a participação na sociedade (ORTEGA, 1999). Retomamos aqui a Declaração de Barcelona, de 2003, na qual se proclama que o educador social é um profissional reflexivo que age a partir da ideia que que a finalidade da ação educativa é a capacitação dos sujeitos para a vida social, a partir da participação social ativa (AIE$\mathrm{JI}, 2003)$. Neste sentido, todos os sujeitos "devem ter a oportunidade de exercer o direito e a responsabilidade de participar nos assuntos da comunidade em que vi- 
vem, envolvendo-se ativamente na resolução dos seus próprios problemas" (CARVALHO \& BAPTISTA, 2004, p. 53). A participação surge, com efeito, como uma condição e um resultado do desenvolvimento social, no pressuposto de que é voluntária, responsável e traduzível num contributo, de concordância ou discordância, relativamente aos processos de desenvolvimento da comunidade (DELGADO, 2006).

No que respeita à formação dos educadores sociais, podemos encontrar um outro desafio para o processo de profissionalização do educador social. Pela exigência da sua missão, o exercício profissional da Educação Social requer dos seus profissionais uma formação rigorosa, tanto inicial como contínua. A educação social resulta de uma pluralidade de saberes que procuram responder às diversas problemáticas sociais. Esta formação deve ser capaz de conferir ao educador social competências de saber, saber ser, estar e fazer que o tornem capaz de agir pedagogicamente e, por isso, deve-se basear numa forte preparação para a caraterização das realidades sociais, para a conceção de projetos socioeducativos, para o trabalho interdisciplinar e para a intervenção em contextos variados. Esta polivalência de saberes reflete-se no perfil profissional dos educadores sociais, na medida em que thes permite assumir diversas funções e papéis.

Os curriculos dos vários cursos de educação social devem procurar aliar a formação científica e prática à formação pessoal da pessoa que é o educador social (VEIGA e CORREIA, 2009), privilegiando metodologias de ensino-aprendizagem que apelem a uma participação ativa dos futuros profissionais na construção de uma postura profissional interventora e reflexiva, capaz de mobilizar os conhecimentos necessários para observar e intervir na realidade social, selecionando objetivos, estratégias e métodos de intervenção de acordo com os contextos e sujeitos, capaz de produzir conhecimento científico.

No entanto, a rápida obsolência dos saberes exige a qualquer profissional uma atualização constante, de forma a adaptar o seu trabalho à realidade que encontra (VEIGA e CORREIA, 2009). A formação permanente é, de facto, essencial para o educador social, pois é por meio dela que o profissional vai incorporando novos saberes e posturas para se adaptar a novos desafios e realidades. Pós-graduações especializadas, mestrados e doutoramentos são desafios para os profissionais, de forma a prepará-los para adquirir novas competências, implicando-os pela construção do seu próprio saber mediante a reflexão sobre as suas próprias práticas (RAMOS, 2006). No entanto, em Portugal, verifica-se ainda um reduzido investimento dos profissionais da Educação Social na formação pós-graduada.

Talvez por este motivo verifica-se ainda um reduzido associativismo socioprofissional. As associações profissionais são fundamentais para a construção da identidade profissional de qualquer profissão. Em primeiro lugar, porque possibilitam a reflexão sobre os valores, princípios e padrões de desempenho que sustentam o "ethos" profissional. Também, porque constituem-se como elementos agregadores da comunidade profissional, estruturando as práticas e credibilizando a atividade profissional. 0 ethos da educação social precisa ser mais valorizado, conhecido e reconhecido. O reconhecimento social é, de facto, decisivo para a valorização de uma profissão (SERAPICOS, 2006). Por outro lado, pertencer a uma associação profissional é participar nos processos de afirmação da identidade profissional, mediante a organização num coletivo profissional coeso, o que se reflete em melhores oportunidades de emprego, maior estabilidade no trabalho, justas remunerações, acesso a cargos hierarquicamente superiores, na criação e organização de espaços de investigação, no apoio profissional, na aproximação a outras entidades nacionais e internacionais, na divulgação do perfil e estatuto profissional do educador social (ASSOCIAÇÃO DOS PROFISSIONAIS TÉCNICOS SUPERIORES DE EDUCAÇÃO SOCIAL,S/d).

As associações profissionais têm um papel decisivo nas questões da ética e da deontologia profissio- 
nal, que deverão constituir uma preocupação central para os educadores sociais e suas entidades representativas. A ética é um dos eixos estruturantes do perfil profissional. De acordo com a Declaração de Barcelona (2003), a ética é um "elemento central da prática profissional”, pois uniformiza decisões, possibilita o questionamento das linhas de atuação profissional. 0 código deontológico é a expressão dos princípios e valores que ajudam a regular comportamentos profissionais. A credibilidade externa, o reconhecimento da educação social e a criação de um órgão representativo e regulador da profissão (a Ordem Profissional) dependem muito da capacidade ética, deontológica e associativa dos profissionais.

A configuração da educação social não pode, ainda, estar desligada das caraterísticas da sociedade atual, marcada pela imprevisibilidade e complexidade, por uma transformação dos valores e ideais. Numa época de crise social generalizada, onde os mecanismos de proteção social deixaram de ser suficientes para diminuir as desigualdades e outros problemas sociais, a pertinência da educação social surge necessariamente reforçada, o que apela a novas responsabilidades e desafios profissionais. Nomeadamente, a realização de ações de sensibilização, petições e outras propostas reivindicativas junto de decisores políticos, alertando-os para os problemas desta profissão (AZEVEDO, 2011).

A educação social deve ser capaz de acompanhar as políticas sociais (DíAZ, 2006), participando permanentemente na negociação do contrato social. Por este motivo, um outro desafio apresentado aos educadores sociais diz respeito à necessidade de revestir a educação social de algum ativismo, aproximando-se mais das pessoas e das suas necessidades, potencialidades e problemas. Atualmente, a ação social e educativa é caraterizada pela concessão de regalias sociais em troca de contrapartidas nas quais os sujeitos não têm qualquer decisão. A isto acresce uma certa pressão social para a regulação e fiscalização, tornando os profissionais em "inspetores sociais" que não encontram espaço para a capacitação dos indivíduos
(TIMÓTEO, 2013). Isto exige uma estratégia criativa e inovadora da educação social (SERAPICOS, 2006).

Uma educação social que se assume transformadora das realidades sociais, deverá ela própria ser transformativa, capaz de ir se adaptando às diversas reconfigurações sociais (TIMÓTEO, 2013). Reforçamos que os educadores sociais, por possuírem um saber tão abrangente, encontram-se numa situação privilegiada para (re)definirem os mapas sociais e educativas das comunidades.

Esta realidade sublinha a importância de identificar, com clareza científica, as problemáticas, as áreas e os âmbitos de intervenção socioeducativa, os seus pressupostos e valores. A Educação Social reclama espaços e práticas profissionais próprios, no âmbito das equipas com quem trabalha, nos quais o educador social desenvolve as suas competências e funções segundo princípios como a dignidade da pessoa e a sua participação voluntária e responsável no seu processo de desenvolvimento. Trata-se, no fundo, de garantir, ou reconhecer, que o trabalho de mediação cultural se encontra inelutavelmente associado a uma dimensão ética, que interroga incessantemente o sentido da liberdade e da justiça (DELGADO e CARDOSO, 2010).

Por fim, destacamos como um último desafio para a educação social em Portugal, a reduzida investigação e produção de publicações que deem visibilidade ao trabalho realizado. A produção de conhecimento é fundamental para a afirmação de qualquer profissão. Os educadores sociais terão de criar conhecimento que torne visível a matriz teórica em que se inscreve a sua praxis profissional. Dada a sua intervenção em contextos sociais diversificados, os educadores sociais precisam de divulgar as suas experiências e boas práticas. Além disso, acreditamos que a escrita favorece a consciencialização profissional, numa atitude crítica e reflexiva das práticas dos profissionais, norteada por um forte compromisso ético. 
Estes são desafios que se colocam à Educação Social em Portugal. Todavia, importa destacar o desempenho profissional dos educadores sociais, capazes de desbravar um espaço de afirmação profissional. É no terreno, no quotidiano profissional que podemos acompanhar os processos de reconfiguração de uma profissão. É nas instituições, nos seus projetos sócio-pedagógicos que estes profissionais desenvolvem e mostram as suas competências e, assim, reconfiguram as suas práticas de intervenção (TIMÓTEO, 2013). A afirmação dos educadores sociais tem vindo a ser construída, em grande parte, a partir das práticas dos próprios profissionais.

\section{REFERÊNCIAS}

AIEJI - International Association of Social Educators (s/data). The Barcelona Declaration 2003. Disponível em: <http://aieji.net/wp-content/uploads/2010/12/ Barcelona-declaration.pdf $>$. Acesso em: 01/04/2014

ASSOCIAÇÃO DOS PROFISSIONAIS TÉCNICOS SUPERIORES DE EDUCAÇÃO SOCIAL (APTSES) (s/data).

Estatutos da Associação dos Profissionais Técnicos Superiores de Educação Social. Disponível em: <http://aptses.pt/sites/default/files//pe/ESTATUTOSAPTS ES.pdf>. Acesso em: 16/03/2014

AZEVEDO, S. Técnicos Superiores de Educação Social. Necessidade e Pertinência de um Estatuto Social. Porto: Fronteira do Caos, 2011

AZEVEDO, S. CORREIA, F. (2013). A Educação Social em Portugal: evolução da identidade profissional. RES - Revista de Educación Social. 17. <http://www. eduso.net/res/pdf/17/ascport_res_17.pdf.>. Acesso em: 01/04/2014

BAPTISTA, I. Educação Social, um espaço profissional com valor e sentido. Espaço(s) de Construção de Identidade Profissional. 55-60. Porto: Universidade Portucalense Infante D. Henrique, 2001.
CABANAS, J. Antecedentes históricos de la Educación Social. In: PETRUS, A. (coord.). Pedagogía Social. Barcelona: Ariel. 1998, p.67-91.

CANASTRA, F. A emergência da profissão do Educador Social: uma aproximação a partir dos processos de profissionalização. Revista de Ciências de Educação. 24.17-32. 2011. Disponível em: <http://www. am.unisal.br/pos/Stricto-Educacao/revista_ciencia/ EDUCACAO_24.pdf>. Acesso em: 01/04/2014

CAPUL, M. LEMAY, M. Da Educação à Intervenção

Social. V.1. Porto: Porto, 2003.

CARIDE, J. Las fronteras de la Pedagogia Social: perspectivas científica e histórica. Barcelona: Gedisa, 2005.

CARIDE, J. TRILLO, F. (Dir.). Dicionario Galego de Pedagoxía. Santiago de Compostela: Xunta de Galicia e Editorial Galaxia. 2010.

CARVALHO, A. BAPTISTA, I. Educação Social. Fundamentos e estratégias. Porto: Porto, 2004.

DELGADO, P: Os Direitos da Criança. Da participação à responsabilidade. Porto. Profedições, 2006.

DELGADO, P. CARDOSO, M. A Educação Social em

Portugal: implantação, realidade actual e desafíos futuros. $3^{\circ}$ Congresso Iberoamericano de Pedagogia Social e XXIV Seminário Interuniversitário de Pedagogia Social. Porto Alegre: Sociedade Ibero-Americana de Pedagogia Social (SIPS), em parceria com a Universidade Luterana do Brasil (ULBRA), 2011.

DÍAZ, A. Uma aproximação à Pedagogia-Educação Social. Revista Lusófona de Educação. 7, 2006, p.91104.

NATORP, P. Pedagogía Social. Teoría de la educación de la voluntad sobre la base de la comunidad. Madrid: Biblioteca Nueva (ed. Original 1898). 2001. 
ORTEGA, J. Educación Social Especializada. Barcelona: Ariel. 1999.

PÉREZ SERRANO, G. Derechos Humanos y Educación Social. Revista de Educación, monográfico Educacíon Social, n.336, 2005, p.19-39.

PÉREZ SERRANO, G. Pedagogía Social - Educación Social. Construcción Cientifica e Intervención Práctica. Madrid: Narcea Ediciones, 2009.

PETRUS, A. Pedagogía Social. Barcelona: Ariel. 1998.

RAMOS, E. A formação dos educadores especializados em âmbito penitenciário na perspectiva da Pedagogia
Social. Revista Portuguesa de Educação. 19 (1). 129152. Braga: CIEd - Universidade do Minho, 2006.

SERAPICOS, A. Alguns desafios que se colocam à Educação Social. Cadernos de Estudo. 3. Porto: Escola Superior de Educação de Paula Frassinetti, 2006, p.7-15.

TIMÓTEO, I. A evolução da Educação Social. Perspetivas e desafios contemporâneos. Praxis Educare. 1, 2013, p.12-18.

VEIGA, S. CORREIA, F. O Perfil do Educador Social. Revista Espaço S - Revista de Investigação e Intervenção Social do ISCE. $2^{a}$ série, n.3. Mangualde: Edições Pedago, 2009, p.55-64.
1. Técnica Superior de Educação Social, Membro executivo da Associação dos Profissionais Técnicos Superiores de Educação Social (APTSES). E-mail: geral@aptses.pt

2. Técnica Superior de Educação Social, Docente na Escola Superior de Educação do Instituto Politécnico do Porto. E-mail: teresamartins@ese.ipp.pt 3. Técnica Superior de Educação Social, Docente na Universidade Portucalense Infante D. Henrique, Docente na Escola Superior de Educação de Fafe, Presidente da Associação dos Profissionais Técnicos Superiores de Educação Social (APTSES). E-mail: sazevedo@uportu.pt

4. Coordenador e Docente no $10^{\circ}$ ciclo de estudos em Educação Social na Escola Superior de Educação do Instituto Politécnico do Porto. E-mail: pdelgado@ese.ipp.pt 